leptischen Methoden des Seifensieders zu ersetzen. Der Seifensieder prüft heute die Alkalität seiner Seifenleime durch Stich, d. h. die Wirkung auf die Zunge. Er bemißt den Salzzusatz nach gewissen optischen Merkmalen. Die Ausarbeitung entsprechender rascher analytischer Orientierungsmethoden am Kessel wird es auch dem über handwerksmäßige Routine nicht verfügenden Chemiker gestatten, gute praktische Resultate zu erzielen. Uber den Rahmen der Kernseifensiederei hinausgehend, kann man auch bei der Schmierseifensiederei als interessante mit dem kolloidalen Zustande zusammenhängende Erscheinung die Wirkung der sogen. Abrichtung erklären. Unter Abrichtung versteht der Seifensieder einen Überschuß an freiem Ätzalkali, welcher zur Erzielung einer gewissen Konsistenz der Seife notwendig ist, welcher also einen integrierenden Bestandteil der Seife darstellt. Stellt man durch Verseifung eines Olansatzes, wie er in der Schmierseifensiederei üblich ist, unter Zusatz der gewöhnlich in Schmierseifen auch enthaltenen Quantitäten Alkalicarbonat eine Seife her, indem man darauf hält, daß die Menge des Ätzalkalis die stöchiometrischen Verhältnisse nicht überschreitet, so erhält man eine dünne, salbige Masse. Ein Zusatz überschüssigen Atzalkalis bewirkt, daß diese Masse zu der handelsüblichen Konsistenz einer Schmierseife erstarrt. Dieser Versuch beweist, daß wir es bei der Abrichtung zweifelsohne mit einem Koagulationsphänomen zu tun haben.

So verspricht die Durchforschung der Seifentechnik unter kolloid-chemischen Gesichtspunkten noch eine reiche Ausbeute. Interessante Versuche liegen von $\mathrm{M}$ e $\mathrm{rk}$ l e $\mathrm{n}$ unter anderem bereits darüber vor, welchen EinfluB die Anwesenheit von Nichtelektrolyten, wie Glycerin, in der Siedelauge besitzt, in welcher Weise durch Wasseraufnahme und -abgabe und entsprechend durch Salzaufnahmeoder -abgabe eine fertige feste Seife durch Einlegen in Salz- resp. Alkalilösungen sich verändert, in welcher Weise schließlich die Temperatur von hervorragendem Einflu $\mathrm{B}_{\mathrm{k}}$ auf die Operationen der Seifensiederei ist. Eine Untersuchung der in Frage kommenden Punkte an definierten Seifen, d. h. Seifen aus reinen, charakterisierten Fettsäuren mit einheitlichen Lösungen definierter Elektrolyte scheint die nächste Aufgabe zu sein für eine theoretische Förderung der Seifenchemie.

\section{Die Verwendung von Calciumnitrat bei Oxydationsschmelzen.}

Mitteilungen aus der analytischen Praxis.

\section{Von Professor Dr. A. Stutzer-Königsberg. (Eingegang. d. 2.j8. 1907).}

In vegetabilischen Stoffen kommen Phosphor und Schwefel zum Teil in organischer Bindung, zum Teil als Sulfat und Phosphat vor. Die Gesamtmenge von Phosphor und Schwefel läßt sich nur durch eine Oxydationsschmelze genau feststellen, da die Gefahr vorliegt, daß bei dem sonst üblichen Veraschen geringe Mengen des Phosphors und Schwefels in Verlust geraten, falls die Asche nicht eine stark alkalische Beschaffenheit hat.
Man pflegt die Oxydationsschmelzen in der Weise zu machen, daß man die organische Substanz mit Kaliumcarbonat oder Natriumcarbonat unter Zugabe von Kaliumnitrat oder Kaliumchlorat mischt und die Mischung allmählich in kleinen Portionen in eine heiße Platinschale einträgt. Handelt es sich um die Zerstörung größerer Mengen von organischer Substanz, so muB ihre Verpuffung mit besonderer Vorsicht ausgeführt werden.

In meinem Laboratorium waren viele Analysen auszuführen, bei denen die Menge des Gesamtschwefels in vegetabilischen Stoffen ermittelt werden mußte. Mit sehr gutem Erfolge bedienten wir uns hierbei des basischen Calciumnitrates, welches nach dem Verfahren von Birkeland-Ey d e fabrikmäßig in großer Menge unter Verwendung des Stickstoffs der atmosphärischen Luft hergestellt wird.

$5 \mathrm{~g}$ der gemahlenen vegetabilischen Substanz werden in einem größeren Tiegel mit $35 \mathrm{~g}$ Calciumnitrat gemengt und weitere $15 \mathrm{~g}$ des Calciumnitrates als Decke oben aufgeschüttet. Man erhitzt zunächst mit einem gewöhnlichen Bunsenbrenner, dann steigert man die Hitze unter Anwendung eines Teclubrenners. Die Masse wird einige Male mit einem Platinspatel umgerührt; wenn die Entwicklung von braunen nitrosen Dämpfen beginnt, entfernt man die Flamme und läßt erkalten. Ein lebhaftes Verpuffen oder Verspritzen findet nicht statt, trotzdem man die ganze Masse auf einmal erhitzt, da die bei der Oxydation der organischen Substanz sich entwickelnde Kohlensäure von dem basischen Kalksalpeter sofort als $\mathrm{CaCO}_{3}$ gebunden wird.

Man läßt die Schmelze erkalten und übergießt sie mit Wasser.

Zum Schmelzen bedienen wir uns Tiegel aus getriebenem Eisen $6 \mathrm{~cm}$ hoch und $8 \mathrm{~cm}$ weit im oberen Durchmesser. Die Schmelze dehnt sich beim Erkalten aus, bei häufigem Gebrauch leiden dadurch die Platinschalen, während Porzellantiegel dabei gar zu leicht zugrunde gehen. Die Eisentiegel sind recht widerstandsfähig, und es war für die von uns bei diesen Analysen zu verfolgenden Zwecke ohne Bedeutung, daß eine geringe Menge Eisen beim Schmelzen oxydiert wird.

Das basische Calciumnitrat wird sich auch für manche andere Oxydationsschmelzen gut verwenden lassen. Vor den bisher üblichen Mischungen für Oxydationsschmelzen hat es den Vorteil, dab diese bereits unter $100^{\circ}$ schmilzt, und gröBere Mengen von Gasen nicht entwickelt werden.

In meinem Laboratorium haben die Assistenten Dr. Reich und Seidler eine große Zahl von Oxydationsschmelzen in dieser Weise ausgeführt; wir sind mit dem Verfahren sehr zufrieden.

\section{Über die Einwirkung von Kohlendioxyd auf die Sulfide des Natriums und des Calciums und von Schwefelwasserstoff auf Natriumcarbonat.}

\author{
Von E. Berl und A. Rittener.
}

Die in der Rohsodalauge des $\mathrm{Le} \mathrm{b} 1 \mathrm{anc}$. Verfahrens enthaltenen Verunreinigungen, wie Nat- 